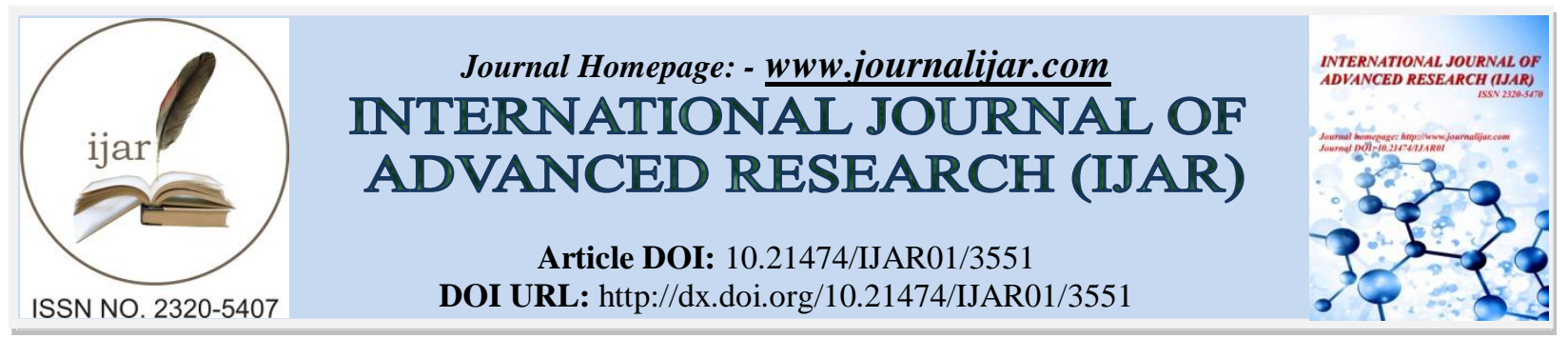

RESEARCH ARTICLE

\title{
A STUDY ON PROBLEMS OF THE ELDERLY PARENTS OF MIGRANT WORKERS
}

\section{T. Geetha.}

Principal Investigator, [MRP-5438/14(SERO-UGC)], Assistant Professor, Department of Social Work, Thanthai Hans Roever College (Autonomous), Perambalur.

\section{Manuscript Info}

Manuscript History

Received: 01 January 2017

Final Accepted: 10 February 2017

Published: March 2017

Key words:-

Aging, Migration, Life satisfaction

\begin{abstract}
Aging is a natural, universal and inevitable with the passage of time. It is a continuous process in end of our life. Old age is the end stage in the life journey and closing period in the life span of a man with decreased capacity for adaptation. The aged are otherwise known as elderly, senior citizen "Geriatric age group" and second child hood. The field of study was dealt with aging and the special problems of the elderly parents of migrant workers. The population of the older persons in India is continuously increasing due to the advancement in medical science, improvement in living conditions and public health facilities have prevented epidemics and brought the general diseases under control. This has increased the life expectancy.

So, the children should extend their support. But due to urbanization, occupation the children are migrated from their own places. The parents are underwent many problems like, physical, psychological. The elderly persons need care and support of the family members. The main objectives of this study were psychological problems of the respondents and level of life satisfaction.
\end{abstract}

Copy Right, IJAR, 2017,. All rights reserved.

\section{Introduction:-}

The term gerontology comes from the Greek word geras meaning 'old age' and logos referring to the study of a subject. The term, gerontology is very broad and encompasses the psychological, socio economic and physiological aspects of old age. Social gerontology is concerned with reciprocal relationship between the individual and society. The term geriatrics deals with causes and amelioration of physical pathology in old age. Senescence, a biological term refers to government that is ruled by elders. Ageism is discrimination against individual on basis of old age. The term geronto phobia is used to designate the fear of growing old or the fear of hatred of the aged. The term ageing refers to the process of growing old.

India has around 100 million elderly at present and the number is expected to increase to 323 million, constituting 20 per cent of the total population, by 2050 .

\section{Review of Literature:-}

Daniel Doyle and Marilyn J. Forehand (2014) made a study on Life Satisfaction and Old Age a Re examination. Using data from a large, representative national sample, this article replicates some earlier analyses regarding life satisfaction and old age. Persons over age 65 were found to be only slightly less satisfied with their lives than persons aged 40 to 54 and 55 to 64. Poor health, loneliness, and money problems are the strongest correlates of life

Corresponding Author:- T. Geetha.

Address:- Principal Investigator, [MRP-5438/14(SERO-UGC)], Assistant Professor, Department of Social 615 
satisfaction across age groups. The small negative correlation between age and satisfaction is largely eliminated when controls for these three factors are imposed. A regression analysis is used to determine the relative strength of a number of possible predictors of life satisfaction within different age groups.

Prakash I.J., (2003) conducted a study on Aging, disability, and disabled older people in India. India is witnessing a demographic revolution, leading to a considerable increase in the proportion of older people in the population. Similarly, life expectancy of both the mentally and physically disabled has improved considerably. About $5 \%$ of Indian older people have problems with physical mobility. Aging has become a gender issue in India not only because more women are surviving into old age; they are also vulnerable and disadvantaged in many ways. In most cases they are the only caregivers available for the old and disabled. Older Indians are considered a high-risk group for multiple morbidity. It is estimated that nearly four million Indians suffer from mental problems. India has around 12 million people designated as "handicapped." However, little information is available about disabled people who grow older. The National Policy on Older Persons, which has been recently formulated, aims at providing an improved quality of life for millions of older Indians. However, the concerns of older disabled and of the disabled who grow old are still treated separately in both policy and practice.

Kalavathy M.C., Thankappan K.R., Sankara sarma P., Vasan R.S. (2000) made a study on prevalence, awareness, treatment and control of hypertension in an elderly community-based sample in Kerala, India. Hypertension is one of the most important causes of cardiovascular morbidity and mortality in the elderly. With the increase in the number of elderly in India, hypertension is likely to emerge as an important public health problem. The study was performed a cross-sectional survey of a random sample of 357 community-dwelling elderly individuals (191women, 166 men; mean age 70 years) in Kerala. We measured blood pressure on all study participants using a standardized technique to assess the prevalence of hypertension. We compared the variations in prevalence, awareness, treatment and control of hypertension according to age, sex and place of residence of the subjects, and examined the socio-demographic correlates of hypertension using specific multiple logistic regression.

The overall prevalence of hypertension sample was 51.8\% (95\% CI;46\% - 56.8\%), Which did not vary with sex but increased with age. Fewer than half of the hypertensive subjects were aware of their condition or were on treatment, and only a quarter of the treated hypertensive achieved adequate control of blood pressure. Rural elderly subjects were especially less likely to be aware of, and on treatment for hypertension. Smoking status and rural residence (in men) and marital status (in women) were important correlates of hypertension. The study findings emphasize the public health importance of hypertension in the elderly in Kerala at present, and point to a likely increase in burden of this problem in India in the near future. A National Hypertension Programme, targeted to meet the imminent public health challenge posed by hypertension seems warranted.

\section{Material and Methods:-}

Objectives:-

- To study the psychological problems of the respondents.

- To study the level of life satisfaction among the respondents.

\section{Hypotheses:-}

- There is significant difference between living arrangement of the respondents and health problem.

- There is significant difference between loneliness of the respondents and their satisfaction in life

- There is significant difference between economic status of the respondents and their standard of living.

Research Design:-

The researcher has used descriptive research design.

\section{Universe}

The universe of the study was Labbaikudikadu town panchayat, Perambalur district.

\section{Sample Size:-}

The researcher adopted simple random sampling to select the elderly people in Labbaikudikadu town panchayat, Perambalur district. So the sample was 800 .

Tool for data collection:-

A self prepared Interview Schedule was used to collect primary data from the respondents.

Hypotheses Test:-

- There is significant difference between living arrangement of the respondents and health problem. 
DIFFERENCE BETWEEN LIVING ALONE AND HEALTH PROBLEM

\begin{tabular}{|l|l|l|l|l|}
\hline S. No & $\begin{array}{l}\text { Living arrangement of the } \\
\text { Respondents }\end{array}$ & Mean & S.D & Statistical inference \\
\hline 1 & Yes (n 706) & 2.46 & 1.738 & $\begin{array}{l}\mathrm{T}=6.07 \\
0.00<0.05 \\
\text { Significant }\end{array}$ \\
\hline 2 & No (n 94) & 1.35 & .936 & $\begin{array}{l}\text { S } \\
\text { y }\end{array}$ \\
\hline
\end{tabular}

Findings:

It is evident from the above table that there is significant difference between living alone and health problem. Hence, the calculated value Less than the table $(0.00<.05)$.

2. There is significant difference between loneliness of the respondents and their satisfaction in life. DIFFERENCE BETWEEN LONELINESS AND SATISFACTION IN LIFE

\begin{tabular}{|c|c|c|c|c|}
\hline S.No & Loneliness of the Respondents & Mean & S.D & Statistical inference \\
\hline 1 & Yes (n 706) & 1.46 & .499 & \multirow{2}{*}{$\begin{array}{l}\mathrm{T}=-.141 \\
0.79>0.05 \\
\text { Not Significant }\end{array}$} \\
\hline 2 & No (n 94) & 1.47 & .502 & \\
\hline
\end{tabular}

Findings:

It is evident from the above table that there is significant difference between living alone and satisfaction in life. Hence, the calculated value Less than the table $(0.79>0.05)$.

3. There is significant difference between economic status of the respondents and their standard of living. DIFFERENCE BETWEEN ECONOMIC STATUS AND STANDARD OF LIVING

\begin{tabular}{|l|l|l|l|l|}
\hline S. No & Economic status of the Respondents & Mean & S.D & Statistical inference \\
\cline { 1 - 4 } 2 & Yes (413) & 10998.84 & 10319.912 & $\begin{array}{l}\text { T= }-1.34 \\
0.003<0.05 \\
\text { Significant }\end{array}$ \\
\hline
\end{tabular}

Findings:

It is evident from the above table that there is significant difference between Economic status of the respondents and standard of living. Hence, the calculated value Less than the table $(0.003<.05)$.

\section{Conclusion:-}

Proper planning for old age is very essential in order to make fuller, happier, richer and graceful aging. Today old age does not necessarily spell death, disease and despair, if one plans ahead for old age. Make efforts to get a steady income during old age. The elderly have been traditionally well-respected and well cared for in Indian culture; experts predict that younger generations in the future are less likely to be concerned and involved in the health care of their older relatives due to urbanization, industrialization or migration not giving much importance to the elderly people. They should consider like child and take care of them. Parents play the vital role to seed the value the next generation to give respect, care and support during the old age period.

\section{References:-}

1. Iliffe, S., Tai, S.S., Haines, A., et al., (1993). Assessment of elderly people in general practice, Depression functional ability and contact with services. The British Journal of General Practice, 43(374): 371-374

2. Park MY, Lee KH, Youn HS, (2001). Nutrition Status of the Rural Elderly Living in Kyungnam, Journal of Community Nutrition, 6, 527-541.

3. Rakesh Singh, Babita Singh, Beulah S Lall, Varidmala Jain (2013). Psychosocial Problems: An Issue among the Elderly in Kathmandu, Nepal. International Journal of Health Sciences and Research, 48-53.

4. Thankappan K.R., Sankara sarma P., Vasan Prevalence R.S., (2000). Awareness, treatment and control of hypertension in an elderly community-based sample in Kerala, India. National Medical Journal of India, 13915.

\section{Website}

1. https://www.ncbi.nlm.nih.gov/pmc/articles/PMC4127891/

2. https://www.ncbi.nlm.nih.gov/pubmed/21366920

3. http://www.ncbi.nlm.nih.gov/pubmedttps://en.wikipedia.org/wiki/Old_age 